\title{
Patterns of invasion in temperate nature reserves
}

\author{
Petr Pyšek ${ }^{\mathrm{a}, *}$, Vojtěch Jarošík ${ }^{\mathrm{b}}$, Tomáš Kučera \\ ${ }^{a}$ Institute of Botany, Academy of Sciences of the Czech Republic, CZ-252 43 Pruihonice, Czech Republic \\ ${ }^{\mathrm{b}}$ Department of Zoology, Faculty of Science, Charles University, Viničná 7, CZ-128 01 Praha 2, Czech Republic \\ ${ }^{\mathrm{c}}$ Institute of Botany, Academy of Sciences of the Czech Republic, Dukelská 135, CZ-379 82 Tr̆ebon̆, Czech Republic
}

Received 18 November 2000; received in revised form 12 May 2001; accepted 15 May 2001

\begin{abstract}
The extent of plant invasions was studied in 302 nature reserves located in the Czech Republic, central Europe. Lists of vascular plant species were obtained for each reserve, alien species were divided into archaeophytes and neophytes (introduced before and after 1500, respectively). The statistical analysis using general linear models made it possible to identify the effects of particular variables. Flora representation by neophytes decreased with altitude (explained $23.8 \%$ of variance) while, with archaeophytes, the effect of altitude depended on their interaction with native species in particular vegetation types. The proportion of neophytes increased with increasing density of human population. Both the number and proportion of aliens plants significantly increased with increasing number of native species in a reserve. This relationship was affected by altitude, and after filtering out this variable, the effect remained positive for neophytes but became negative for archaeophytes in humid grasslands. The positive relationship between neophytes and native species is not a mere side effect of species-area relationship of native flora, but indicates that the two groups do not directly compete. Vegetation type alone explained 14.2 and $55.5 \%$ of variation in proportion of aliens in regions of mesophilous and mountain flora, respectively. Humid grasslands were the least invaded vegetation type. Positioning the reserve within large protected sections of landscape significantly decreases probability of it being invaded by potentially invasive alien species. Within the context of SLOSS debate, a new model - several small inside single large (SSISL) - is suggested as an appropriate solution from the viewpoint of plant invasions to nature reserves. (C) 2002 Elsevier Science Ltd. All rights reserved.
\end{abstract}

Keywords: Alien plants; Native species; Nature reserves; Temperate flora; Climate; Altitude; SLOSS; Czech Republic; Central Europe

\section{Introduction}

Biological invasions have become an important field of ecology and recently received considerable global attention (Groves and Burdon, 1986; Macdonald et al., 1986; Mooney and Drake, 1986; Kornberg and Williamson, 1987; Drake et al., 1989; Pyšek et al., 1995; Rejmánek, 1996, 1999; Davis et al., 2000; Richardson et al., 2000a). The introduction of plant species from one region to another is closely related to human activities and considerable effort has therefore been invested in studying patterns of plant invasions in urban environments and other disturbed habitats harbouring high proportions of alien species (Kowarik, 1990, 1995; Pyšek, 1998). However, invasions into natural vegetation have always been of special importance. All alien

\footnotetext{
* Corresponding author.

E-mail addresses: pysek@ibot.cas.cz (P. Pyšek), jarosik@mbox. cesnet.cz (V. Jarošík), kucera@butbn.cas.cz (T. Kučera).
}

species represent potential endangerment to nature reserves (Cole and Landres, 1996), and those that are able to naturalize or become invasive (see Richardson et al., 2000b for terminology) can replace native flora or even change ecosystem properties (Vitousek, 1990; Gordon, 1998) and cause management problems (Berger, 1993). The knowledge of factors determining an alien plant's occurrence is a necessary condition for effective control. Nature reserves also represent a suitable laboratory for studying the nature and effectiveness of barriers that alien species must overcome to become naturalized or invasive (Richardson et al., 2000b).

The importance of nature reserves varies in particular regions of the world and depends on the degree to which the landscape has been transformed by humans (Duffey and Usher, 1988). Studies to date in various kinds of nature reserves (national parks, biospheric reserves, small-scale nature reserves) have yielded some generalization at a global level (Macdonald et al., 1989). Tropical 
and arid subtropical reserves seem to be less invaded because of less extreme conditions (Holdgate, 1986). Reserves situated on islands are more vulnerable than those located on mainlands (Brockie et al., 1988; Holt, 1992). The degree to which a nature reserve is invaded, is closely related to the number of human visitors (Usher, 1988; Lonsdale, 1999). Alien species occur in all nature reserves, including those in the tropics (Usher, 1988, 1991) and predictions are made that the importance of alien species in nature reserves will increase in the future unless effective control measures are adopted (Macdonald et al., 1989). More recently, it was shown that nature reserves over the world are invaded about half as often as sites outside reserves (Lonsdale, 1999).

As far as temperate climatic regions are concerned, the situation is less disturbing in the Northern (Loope, 1992) than in the Southern Hemisphere (Usher et al., 1988). However, no comprehensive study has hitherto been devoted to a detailed pattern of plant invasions into temperate nature reserves. The territory of the Czech Republic represents a suitable model for studies of plant diversity at a wider landscape scale and makes it possible to analyse the regional pattern of plant invasions into a representative set of natural temperate plant communities (Pyšek et al., 2001). The region has variable orography, climate, geology and a number of different habitats can be found even in small areas. Environmental conditions favour the development of rich flora, typical of central Europe. The prevailing climate supports forest expansion (Hejný and Slavík, 1988). A long-term tradition of nature protection resulting in a dense network of nature reserves ensures that major vegetation types are represented in the system of nature reserves within a relatively large-scale and diverse region (Maršálková-Němejcová and Mihálik, 1977).

The present paper is directed first to answering the questions associated with theoretical principles of plant invasions, i.e. (1) what are the main abiotic factors determining the extent of invasion by alien plant species into remnants of central European natural vegetation? (2) What is the effect of native species on the extent of invasions, and is there any direct relationship between native and alien species? We then use the data to test practical questions which are relevant for nature conservation authorities: (3) How do factors such as size and location of reserves influence the extent to which it will be exposed to invasion by alien species?

\section{Methods}

\subsection{Data sources}

The present study uses data from nature reserves protected under the nature conservation system of the Czech Republic. The area studied covers $78854 \mathrm{~km}^{2}$ within the latitudinal range of $48^{\circ} 30^{\prime}-51^{\circ} 05^{\prime}$ and longitudinal range of $12^{\circ} 05^{\prime}-18^{\circ} 50^{\prime}$. In 1996, there were 1757 small-sized protected nature reserves in the Czech Republic, covering an area of $82.3 \mathrm{~km}^{2}$, i.e. $1.05 \%$ of the territory of the country (Kos and Maršálková, 1997). Of these, 302 had suitable data for the present study, and represent $17.2 \%$ of the total number of reserves. Most of the important, larger reserves covering major habitats were included giving a total sampled area of $36.5 \mathrm{~km}^{2}$ (accounting for $0.46 \%$ of the country territory, and $44.2 \%$ of the total area of nature reserves).

Species lists were obtained for each of the 302 nature reserves used in the study, from published records from particular reserves as well as unpublished floristic inventories deposited at the Agency for Landscape Protection of the Czech Republic, Prague. These inventories are carried out regularly by professional botanists who are asked to collect data with standardized methods. Vascular plant species were classified into native and alien, the latter group further divided in (1) archaeophytes, i.e. introduced to the country before A.D. 1500, and (2) neophytes, introduced after that date. This classification system corresponds to one widely used in central-European phytogeographical studies (e.g. Holub and Jirásek, 1967; Schroeder, 1969 for details, and Pyšek, 1995 for comparison with other systems). The only difference is that we did not attempt to distinguish between taxa introduced by humans from those having arrived accidentally because this information is not generally available, and included both of these groups under "neophytes".

Numbers of plant species in each of the three groups (native, archaeophytes, neophytes) as well as the total species number were recorded for each reserve. The number of all aliens (further termed just "aliens") was obtained by summing the numbers of archaeophytes and neophytes.

For each nature reserve, the following characteristics were obtained:

1. Reserve area.

2. Mean altitude, expressed as the middle value between minimum and maximum altitude recorded at the reserve territory.

3. Number of native species was used to investigate the effect of native flora on the extent of invasion; as shown by Lonsdale (1999), this characteristic also serves as a suitable surrogate for habitat diversity.

4. Position of the reserve within the system of protected areas, i.e. whether or not it was located within large-scale protected areas such as national park and protected landscape areas.

5. Density of human population (number of inhabitants per $\mathrm{km}^{2}$ ) in the respective administrative 
district was taken as a measure of severity of human impact; the country consists of 77 districts of average size $1024.9 \pm 394.1 \mathrm{~km}^{2}$ (mean \pm S.D.).

6. Prevailing vegetation type covering most of the reserve area. The following categories were recognized: pine forest; beech forest; acidophilous oak forest; hornbeam forest; spruce forests; scree and ravine forests; humid grasslands, i.e. meadows, pastures and saline habitats; wetlands, including pond shores and alder forests; mires, peat bogs and fens; dry grasslands, i.e. steppe vegetation including scrub in dry habitats.

7. Phytogeographical region in which a reserve is located. Three basic regions were recognized: Thermophyticum, i.e. a region of thermophilous flora and vegetation; Mesophyticum with mesophilous flora and vegetation; Oreophyticum with mountain flora and vegetation-Hejný and Slavík, 1988.

8. Climatic district: warm, moderately warm, and cold (Quitt, 1975).

9. January isotherm (mean annual temperature in January).

Other climatic explanatory variables, i.e. annual total precipitation, mean annual temperature and June isotherm (mean annual temperature in June), appeared always non-significant in the process of model simplifications. The climatic parameters were obtained from GIS layers built by digitalizing the relevant maps (Vesecký et al., 1958, 50-year averages).

\subsection{Statistical analysis}

The data were evaluated by analysis of covariance (ANCOVA) with logit proportion of aliens in individual reserves as the response variable. Among the explanatory variables, prevailing vegetation type, phytogeographical region, climatic district, and position of the reserve were treated as factors, whilst number of native species occurring in the reserve (range 11-547), reserve area (0.17-4280 ha), density of human population (60500 inhabitants per $\left.\mathrm{km}^{2}\right)$, mean altitude $(150-1362 \mathrm{~m}$ a.s.l), annual sum of precipitation (475-1700 mm), mean annual temperature $\left(1.0-9.5{ }^{\circ} \mathrm{C}\right)$, January isotherm $\left(-7.5\right.$ to $\left.-1.0^{\circ} \mathrm{C}\right)$, and June isotherm $(8.0$ $18.0^{\circ} \mathrm{C}$ ) were treated as covariates. Calculations were made using general linear modelling (McCullagh and Nelder, 1989) in the statistical package GLIM $^{\circledR}$ v. 4 (Francis et al., 1994). The response variable, i.e. the logit of alien proportion $p$ in each reserve, was expressed as $\ln [p /(1-p)]$ where $p$ was the proportion of aliens in the total number of species in each reserve (aliens plus native). The logit is a linearization technique that in GLIM $^{\circledR}$ provides the link function relating the linear predictor, $a+b x$, to the value of the response variable by expression (see Crawley 1993, pp. 266-268). $\ln \left(\frac{p}{1-p}=a+b x\right)$

To prevent the logits of the aliens estimated from small samples having an undue influence on the values of the statistical models, the logits were weighted by the total number of species in each reserve.

The analysis was first made with the logit proportion of the total number of alien species in each reserve as the response variable, and then carried out separately for the number of archaeophytes and that of neophytes as response variables. The purpose of each analysis was to determine the minimal adequate model. In this model, all parameters were significantly $(P<0.05)$ different from zero and from one another. This was achieved by a step-wise process of model simplification, beginning with the maximal model (containing all factors, interactions and covariates that might be of interest), then proceeding by the elimination of nonsignificant terms (using deletion tests from the maximal model), and retention of significant terms. Standardized residuals of each analysis were determined, and the analysis was repeated on the standardized residuals as the response variables assuming identity link function and normal errors. The analysis of residuals was repeated on all possible combinations of residuals of significant explanatory variables until all the explanatory variables were insignificant. To gain a complete inventory of the pure effects, all significant results, including those explaining little variance, were listed.

Because the explanatory variables were often highly correlated, model simplifications were made by backward elimination from the maximal models using step-wise analyses of deviance tables to prevent biases to the model structures caused by correlation. In the maximal model, each covariate was regressed on each factor with a different intercept and a different slope. In the first step of model simplification, the different slopes of each covariate on each factor were in turn replaced by a common slope of each factor on each covariate. The common slopes were regressed on the factors one after another, and changes in residual deviance caused by removal of the different slopes for each covariate were assessed. After all covariates with a common slope were assessed, then all non-significantly different slopes were deleted, and a reduced model was assessed. The analysis then continued with the reduced model. In this model, all the remaining terms were deleted in turn from the reduced deviance table, and only those leading to a significant increase in residual deviance were retained. The deletion tests were repeated on the reduced models until, after removal from the last deviance table, the minimal adequate model that only contained significant terms was determined. Thus, the results obtained were not affected by the order in which the explanatory variables were removed in the step-wise process of model simplification. 
The errors in the response variables when expressed as logits were assumed to be binomially distributed. This assumption is appropriate for fitting proportional data (Cox and Snell, 1990) but the adequacy of binomial errors must be checked for overdispersion. Williams' adjustment for unequal binomial denominators was used (Crawley, 1993, pp. 351-353). In this procedure, an iterative estimate for $\Phi$ in the equation:

$\sigma_{\mathrm{jk} l}^{2}=1+\left(n_{\mathrm{jk} l}-1\right) \Phi$

was determined by equating the value of Pearson's $\chi^{2}$ statistic for the model to its appropriate expected value, then using $1 / \sigma_{\mathrm{jk} 1}^{2}$ as a weight for the individual binomial observations (see Collet, 1991, for details). Because the minimal adequate models using logits did indicate overdispersion, the analyses were repeated on deviance tables inflated for the overdispersion determined by the Williams procedure.

All covariates were standardized (zero mean, variance one) to achieve comparable influence (in absolute values) of each covariate parameter. Data on numbers of native species in each reserve were transformed (square root), and data on numbers of alien species (that included zeros) were also transformed by the square root and coded by adding 0.5 (e.g. Sokal and Rohlf, 1981, pp. 421-423). The adequacy of fitted models was checked by plotting standardized residuals against fitted values, and by the normal probability plots of the fitted values (Crawley, 1993).

\section{Results}

\subsection{Overall proportion of aliens in reserves}

Across all sites (reserves), the mean proportion of aliens was $6.1 \%$ (range $0-25 \%$ ), of which archaeophytes contributed $4.1 \%(0-20.8 \%)$ and neophytes $2.0 \%(0-$ $11.6 \%$ ). The correlation between the proportion of neophytes and archaeophytes was $r=0.62$. Frequency distributions were right skewed (Fig. 1), 11.6\% of all nature reserves being without aliens, $17.2 \%$ without archaeophytes, and $24.2 \%$ harbouring no neophytes. In terms of species numbers, there were 1840 native species (85.1\% of the total), 153 archaeophytes $(7.1 \%)$, and 169 neophytes $(7.8 \%)$ in the reserves studied.

The Czech flora is estimated to contain up to 2300 native species (Holub and Procházka, 2000) of which $80 \%$ are present in the nature reserves studied in this paper. Corresponding data for alien plants is estimated at about 1200 species (Pyšek, Mandák and Sádlo, unpubl. data; $27 \%$ present) of which about 250 are archaeophytes (Opravil, 1980; 61\% present) and remaining are neophytes $(18 \%$ of which are present in the reserves studied). These data indicate that the fraction of alien plants invading nature reserves compared to the total number of species present in the country's flora is disproportionally lower for neophytes than archaeophytes.

\subsection{Effect of altitude, climate and human impact on the representation of aliens}

Taken together, the variables used explained $44.0 \%$ of variation in the representation of all alien plants, $26.6 \%$ in archaeophytes, and $23.8 \%$ in neophytes (Table 1).

The proportion of aliens and that of neophytes (Fig. 2A) decreased with increasing altitude (Table 1). Altitude had no effect on the proportion of archaeophytes in the minimal adequate model (Table 1) but appeared significant if the interaction of the number of native species with prevailing vegetation type is filtered out (Fig. 2B).

The decreasing proportion of aliens at higher altitudes was to a large extent due to the colder climate. When the effect of altitude is removed, proportion of aliens was significantly affected by the climatic district, and increased from cold to moderate to warm climates. The proportion of aliens in the moderate climatic district significantly increased with increasing January isotherm (Table 2).

The proportion of neophytes was positively affected by the density of human population in the region once the effect of altitude was filtered out. No significant effect of human population density on the proportion of either archaeophytes or all aliens was found (Table 2).

In order to reveal how the effect of abiotic factors on the proportion of alien species interacted with reserve area, we filtered out the reserve area from the models (Tables 1,2). By doing this, we found that the effect of altitude on the representation of aliens in a reserve was partly mediated through the reserve area (percent of explained variation decreased from 26.0 to 16.5 ) but the influence of climate and human density was not markedly affected by it. This is a result of the fact that the reserve area changes with altitude (standardised area $=0.000044+0.33$ standardised altitude, $F=36.28$; d.f. $=1,300 ; P<0.001, R^{2}=10.8 \%$ ).

\subsection{Effect of native species and reserve area}

Simple regression of the number of aliens on the number of native species yielded a positive relationship and explained $70 \%$ of variance in the data set (Fig. 3), corresponding values for archaeophytes and neophytes being 66 and $72 \%$, respectively. Likewise, the proportion of aliens significantly increased with increasing number of native species in a reserve (Table 1). However, after filtering out the effect of altitude (which is not only the main determinant of representation of alien species but also affects the number of native speciesPyšek et al., 2001), we found an increasing proportion 
of neophytes but a decreasing proportion of all aliens with the number of native species (Table 2).

The proportion of archaeophytes in a reserve was not significantly affected by the number of native species but was affected by the interaction of this variable with prevailing vegetation type. The proportion of archae- ophytes increased with the number of native species in the reserves with the vegetation types of beech forest, wetland, mires and dry grasslands, while the opposite was true in humid grasslands (Table 1). For neophytes, no significant interaction between the number of native species and prevailing vegetation type was found.

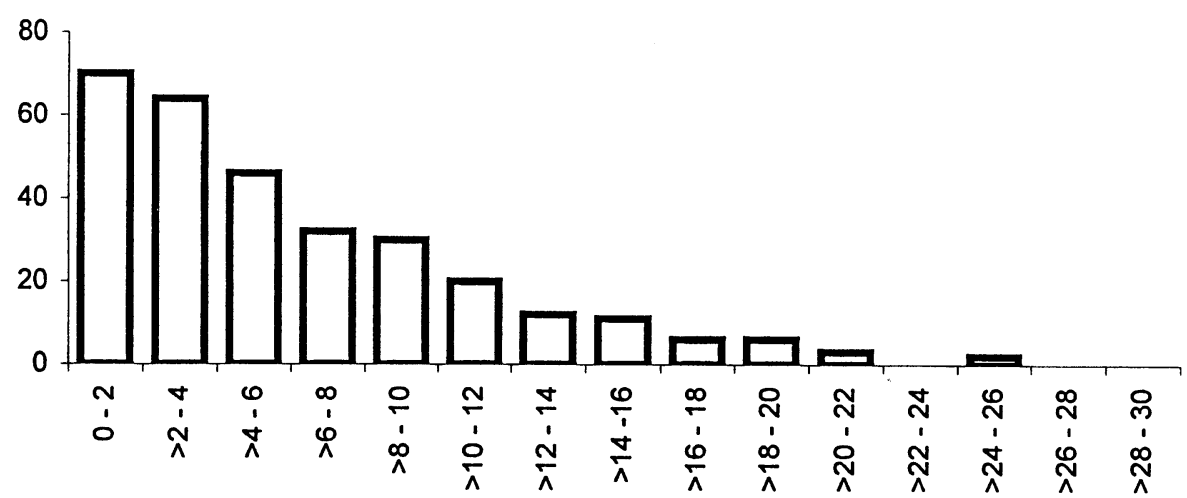

B
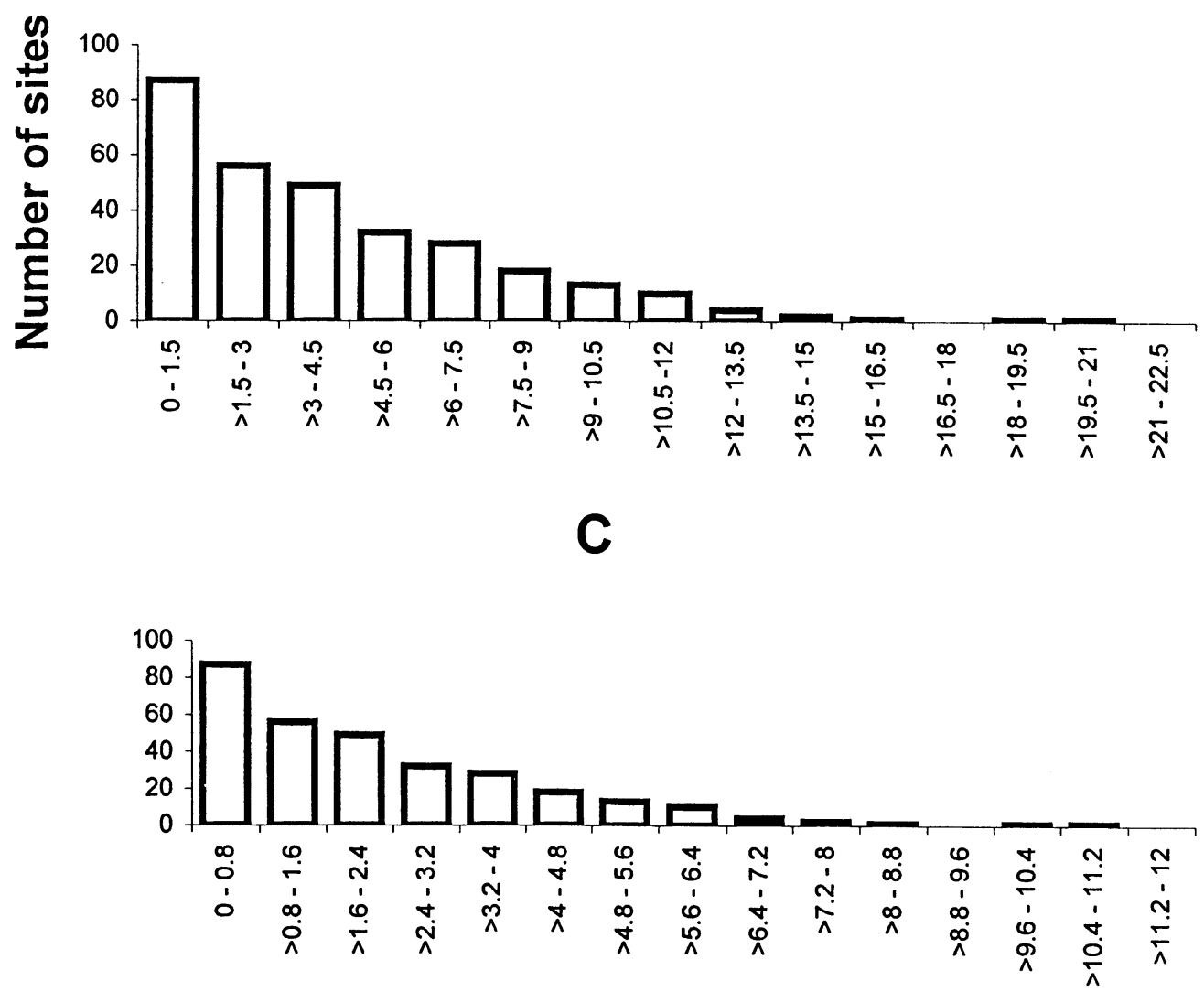

$\%$ representation

Fig. 1. Frequency distributions of proportional representation of all (A) aliens, (B) archaeophytes and (C) neophytes shown for all sites, i.e. 302 nature reserves located in the Czech Republic. 
This complex effect of the richness of native flora on the pattern of occurrence of aliens depends, to some extent, on the area available to native species. Proportion of aliens alone did not significantly depend on reserve area $\left(\chi^{2}=0.05\right.$; d.f. $\left.=1 ; P=0.82\right)$, and even the relationship between the number of aliens in a reserve and its area was at the limits of significance $(F=3.75$; d.f. $\left.=1,300 ; P=0.054 ; R^{2}=1.2 \%\right)$. When the effect of native species was filtered out, the proportion of aliens was positively correlated with area but the relationship was rather weak explaining only $2.3 \%$ of variation (Table 3).

To reveal the direct relationship (i.e. not biased by the area) between alien and native species, the effect of reserve area was filtered from the number of native species in analyses indicating a significant relationship between both groups of taxa. After doing this, the relationships remained highly significant (with the one

Table 1

Significant explanatory variables of minimal adequate model of logit-weighted proportions of all aliens, archaeophytes, and neophytes with William's adjustment of binomial errors ${ }^{\mathrm{a}}$

\begin{tabular}{|c|c|c|c|c|c|c|c|c|c|}
\hline \multirow[t]{2}{*}{ Explanatory variables } & \multicolumn{3}{|l|}{ Aliens } & \multicolumn{3}{|l|}{ Archaeophytes } & \multicolumn{3}{|l|}{ Neophytes } \\
\hline & Slope \pm S.E. & $\chi^{2}$ & $R^{2}(\%)$ & Slope \pm S.E. & $\chi^{2}$ & $R^{2}(\%)$ & Slope \pm S.E. & $\chi^{2}$ & $R^{2}(\%)$ \\
\hline Mean altitude & $\begin{array}{c}-0.54 \pm 0.05 \\
(-0.47 \pm 0.05)\end{array}$ & $\begin{array}{l}134.80 * * * \\
(84.0 * * *)\end{array}$ & $\begin{array}{l}26.0 \\
(16.5)\end{array}$ & & NS & & $-0.56 \pm 0.06$ & $93.04 * * *$ & 23.8 \\
\hline No. native species & $\begin{array}{c}0.26 \pm 0.04 \\
(0.094 \pm 0.01)\end{array}$ & $\begin{array}{c}52.78 * * * \\
(54.45 * * *)\end{array}$ & $\begin{array}{l}10.2 \\
(10.7)\end{array}$ & & NS & & & NS & \\
\hline \multicolumn{10}{|c|}{ No. native species in reserves with prevailing: } \\
\hline Beech forests & & NS & & $\begin{array}{c}1.20 \pm 0.25 \\
(0.35 \pm 0.07)\end{array}$ & $\begin{array}{l}29.62 * * * \\
(36.29 * * *)\end{array}$ & $\begin{array}{l}7.3 \\
(8.7)\end{array}$ & & NS & \\
\hline Humid grasslands & & NS & & $\begin{array}{c}-1.13 \pm 0.27 \\
(-0.09 \pm 0.09)\end{array}$ & $\begin{array}{l}14.09 * * * \\
(1.05 \mathrm{NS})\end{array}$ & $\begin{array}{l}3.7 \\
(-)\end{array}$ & & NS & \\
\hline Wetlands & & NS & & $\begin{array}{c}0.25 \pm 0.10 \\
(0.09 \pm 0.03)\end{array}$ & $\begin{array}{l}5.87 * \\
(6.89 * *)\end{array}$ & $\begin{array}{l}1.4 \\
(1.7)\end{array}$ & & NS & \\
\hline Peat bogs & & NS & & $\begin{array}{c}0.42 \pm 0.09 \\
(0.18 \pm 0.03)\end{array}$ & $\begin{array}{l}18.66 * * * \\
(35.82 * * *)\end{array}$ & $\begin{array}{l}4.6 \\
(8.6)\end{array}$ & & NS & \\
\hline Dry grasslands & & NS & & $\begin{array}{c}0.33 \pm 0.05 \\
(0.13 \pm 0.02)\end{array}$ & $\begin{array}{l}34.01 * * * \\
(50.57 * * *)\end{array}$ & $\begin{array}{l}8.3 \\
(12.2)\end{array}$ & & NS & \\
\hline
\end{tabular}

a Covariates are indicated by standardized slope \pm one standard error (S.E.). Figures in parentheses are values of explanatory variables after filtering out the reserve area. NS $=$ non-significant; d.f. $=1$ for all models. Total explained variance: aliens: $R^{2}=44.0 \%(55.4 \%)$; archaeophytes: $R^{2}=26.6 \%(32.8 \%)$ neophytes: $R^{2}=23.8 \%$.

${ }^{*} P<0.5$.

** $P<0.01$.

*** $P<0.001$.

Table 2

Significant explanatory variables of minimal adequate model of residuals of the logit proportions of all aliens and neophytes (archaeopytes are not presented because altitude was not significant in the minimal adequate model, see Table 1) after filtering out the effect of mean altitude ${ }^{\mathrm{a}}$

\begin{tabular}{|c|c|c|c|c|c|c|c|c|}
\hline \multirow[t]{2}{*}{ Explanatory variables } & \multicolumn{4}{|l|}{ Aliens } & \multicolumn{4}{|l|}{ Neophytes } \\
\hline & Slope \pm S.E. & $F$ & d.f. & $R^{2}(\%)$ & Slope \pm S.E. & $F$ & d.f. & $R^{2}(\%)$ \\
\hline \multirow[t]{2}{*}{ Prevailing vegetation type } & - & $4.69 * * *$ & 9,297 & 8.5 & - & $3.40 * * *$ & 9,299 & 8.4 \\
\hline & $(-)$ & $(4.94 * * *)$ & $(9,297)$ & $(9.2)$ & $(-)$ & $(3.82 * * *)$ & $(9,299)$ & (9.9) \\
\hline \multirow[t]{2}{*}{ Climatic district } & - & $45.15 * * *$ & 2,290 & 18.2 & & NS & & \\
\hline & $(-)$ & $(44.10 * * *)$ & $(2,290)$ & $(18.2)$ & & & & \\
\hline \multirow{2}{*}{$\begin{array}{l}\text { January isotherm in the moderately } \\
\text { warm climatic district }\end{array}$} & $0.44 \pm 0.15$ & $9.26 * *$ & 1,289 & 1.9 & & & & \\
\hline & $(0.45 \pm 0.15)$ & $(8.81 * *)$ & $(1,289)$ & $(1.8)$ & & & & \\
\hline \multirow[t]{2}{*}{ Density of human population } & & NS & & & $0.15 \pm 0.06$ & $7.42 * *$ & 1,291 & 2.0 \\
\hline & & & & & $(0.16 \pm 0.06)$ & $(8.34 * *)$ & $(1,291)$ & $(2.4)$ \\
\hline \multirow[t]{2}{*}{ No. native species } & $-0.27 \pm 0.06$ & $17.41 * * *$ & 1,289 & 3.5 & $0.28 \pm 0.06$ & $21.85 * * *$ & 1,291 & 6.0 \\
\hline & $(-0.067 \pm 0.02)$ & $(10.55 * * *)$ & $(1,289)$ & $(2.2)$ & $(0.052 \pm 0.02)$ & $(8.05 * *)$ & $(1,291)$ & $(2.3)$ \\
\hline
\end{tabular}

${ }^{a}$ Covariates are indicated by standardized slope \pm one standard error (S.E.). Figures in parentheses are values of explanatory variables after filtering out the reserve area. Significance level is indicated. Total explained variance: aliens total: $R^{2}=41.9 \%(40.6 \%)$; neophytes: $R^{2}=20 \%(16.3 \%)$. $\mathrm{NS}=$ non-significant.

${ }^{*} P<0.05$.
${ }^{* *} \quad P<0.01$.
${ }^{* * *} \quad P<0.001$. 
exception of archaeophytes in humid grasslands) while the slopes of the regression lines, characterizing the proportion of aliens regressed on the number of native species, were markedly lower; other parameters of the respective models changed only slightly (Tables 1,2 ). Hence the reserve area in all but one case strongly affects only the intensity, but not the very existence of the relationships between the proportion of aliens and the number of native species occurring in a reserve. The positive relationships between the number of native species and proportion of aliens in a reserve are thus not mere side effects of species-area relationship of native flora. However, the negative effect of native flora on archaeophytes in humid grasslands is mediated through the area rather than a direct one.

\subsection{Effect of the prevailing vegetation type}

To reveal the effect of prevailing vegetation type on the proportion of aliens, we removed the two main abiotic determinants, i.e. altitude and climate. In the resulting model, a significant interaction was found between prevailing vegetation type and phytogeographical district:

\section{A}

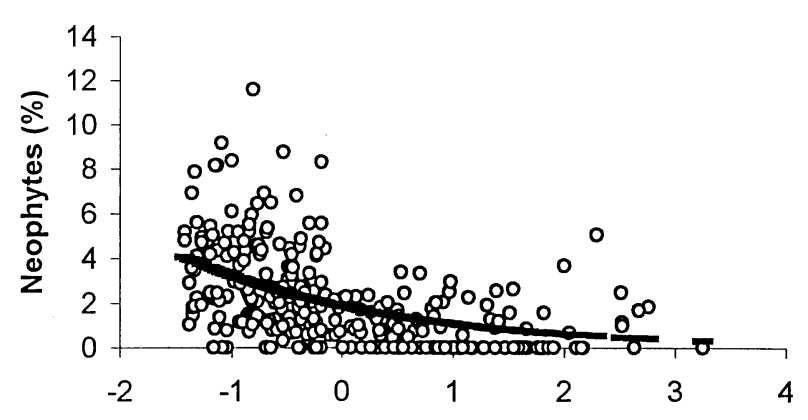

B

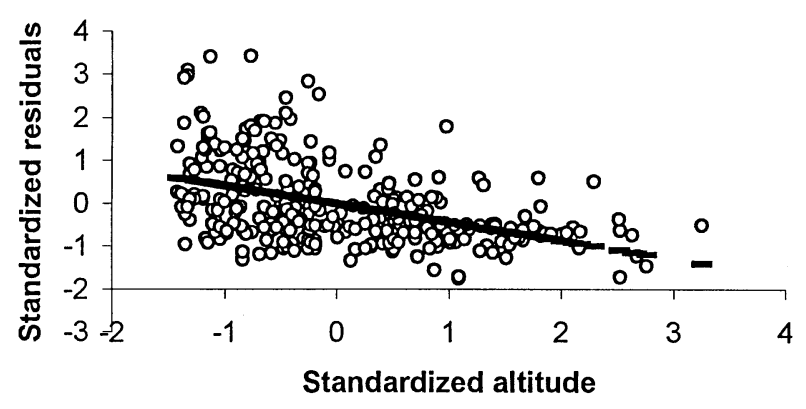

Fig. 2. The relationship between logit-weighted proportion of (A) neophytes, (B) standardized residuals of archaeophytes after filtering out the interaction between the number of native species and prevailing vegetation types, and the standardized altitude. A: logit weighted proportions of neophytes $=-3.96 \pm 0.057-0.56 \pm 0.065$ standardized altitude $\left(\chi^{2}=93.04\right.$; d.f. $\left.=1 ; P=5.12^{-22} ; R^{2}=23.8 \%\right)$. B: standardized residuals of archaeophytes $=-0.026( \pm 0.050)-0.43( \pm 0.05)$ standardised altitude $\left(F=73.59\right.$; d.f. $\left.=1,300 ; P=5.24^{-16} ; R^{2}=19.7 \%\right)$. the vegetation type was indicated as the only significant predictor of alien representation in the districts of mesophilous and mountain flora, explaining $14.2 \%$ of residual variation in the former and $55.5 \%$ in the latter (Table 4).

The representation of aliens in the districts of mesophilous and mountain flora was markedly lowest in reserves dominated by humid grasslands (Fig. 4). Although the proportion of aliens in humid grasslands did not differ significantly from that in dry grasslands, spruce and acidophilous oak forests in the district of

Table 3

Significant explanatory variables of minimal adequate model of residuals of the logit proportions of all aliens after filtering out the effect of the number of native species. Covariates are indicated by standardized slope \pm one standard error (S.E.) ${ }^{\mathrm{a}}$

\begin{tabular}{|c|c|c|c|c|c|}
\hline \multirow[t]{2}{*}{ Explanatory variables } & \multicolumn{5}{|l|}{ All aliens } \\
\hline & Slope \pm S.E. & $F$ & d.f. & $P$ & $R^{2}$ \\
\hline Prevailing vegetation type & - & 7.06 & 9,299 & $<0.0001$ & 15.7 \\
\hline Reserve area & $0.21 \pm 0.07$ & 9.34 & 1,291 & 0.002 & 2.3 \\
\hline
\end{tabular}

a Total explained variance $R^{2}=25.0 \%$.
Table 4

Significant explanatory variables of minimal adequate model of residuals of the logit proportions of all aliens after filtering out the effect of mean altitude, climatic district, and the interaction of the latter with January isotherm

\begin{tabular}{lcccc}
\hline Explanatory variables & \multicolumn{4}{l}{ All aliens } \\
\cline { 2 - 5 } & $F$ & d.f. & $P$ & $R^{2}$ \\
\hline $\begin{array}{l}\text { Phytogeographical } \\
\text { district } \times \text { vegetation type }\end{array}$ & 2.05 & 14,276 & 0.01 & - \\
$\begin{array}{l}\text { Vegetation type in the } \\
\text { district of temperate flora }\end{array}$ & 2.74 & 9,149 & 0.0005 & 14.2 \\
$\begin{array}{l}\text { Vegetation type in the } \\
\text { district of mountain flora }\end{array}$ & 12.07 & 6,58 & $<0.0001$ & 55.5 \\
\hline
\end{tabular}

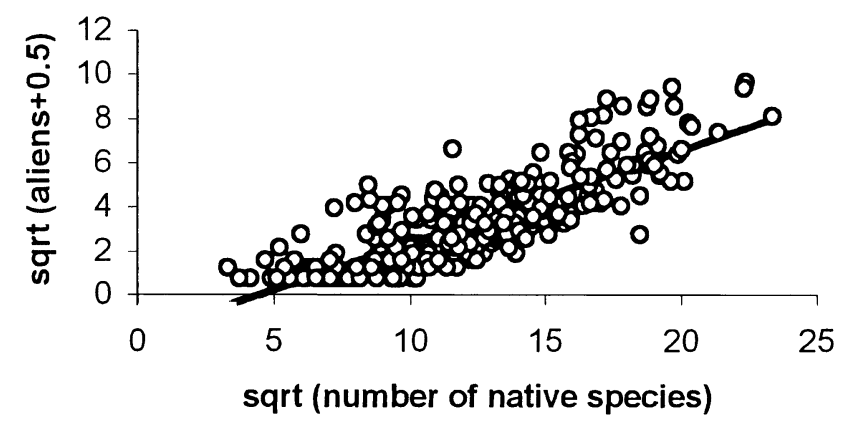

Fig. 3. The relationships between the number of aliens and number of native species: $\sqrt{ }$ (number of aliens +0.5$)=-1.91 \pm 0.22+0.42 \pm 0.02$ $\sqrt{ }$ number of native species $\left(F=608.6 ;\right.$ d.f. $=1,300 ; \quad P=3.64^{-74}$; $\left.R^{2}=70 \%\right)$. 

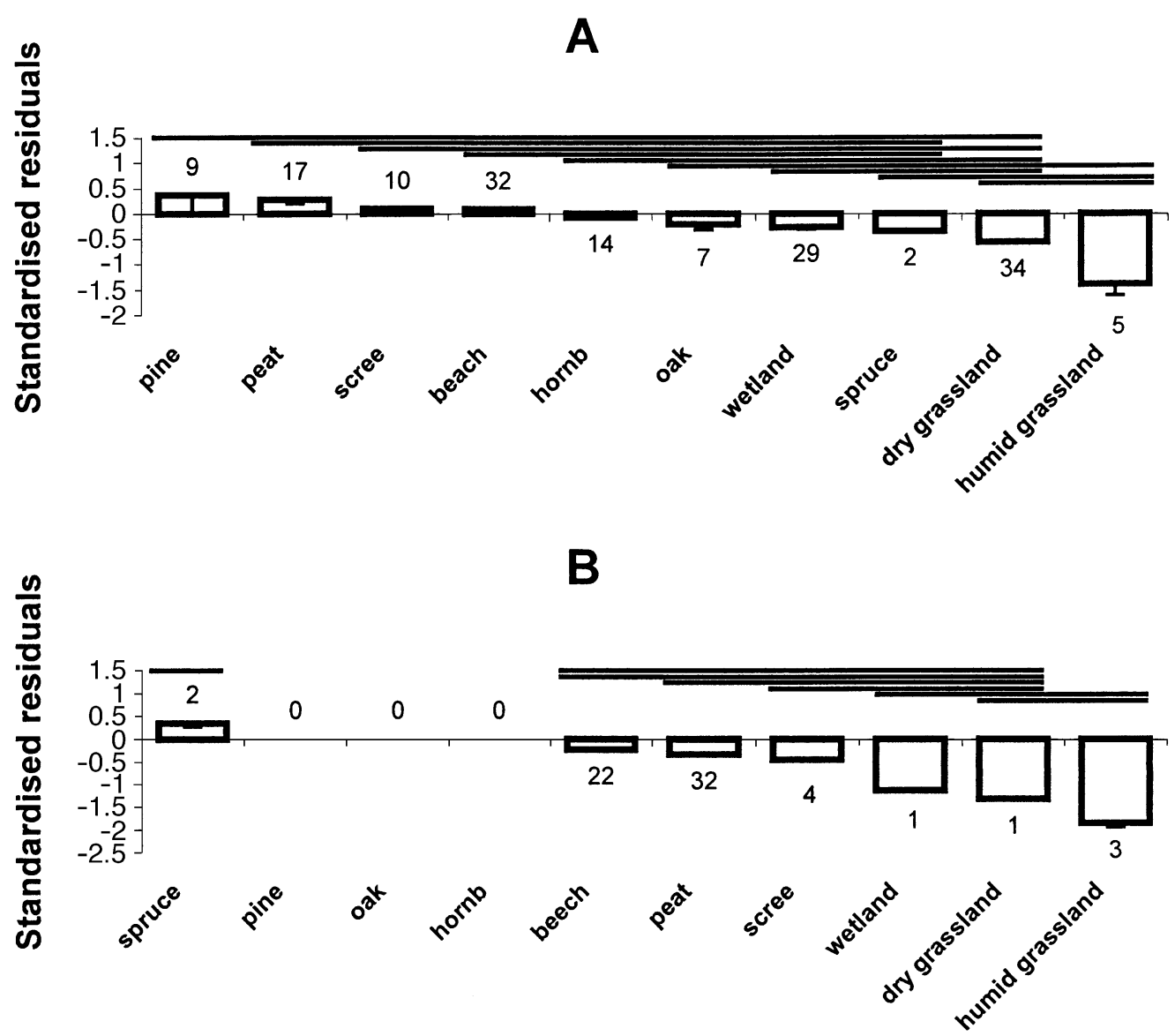

Fig. 4. Standardized residuals of the proportion of aliens in particular prevailing vegetation types in the phyteogeographical district of mesophilous (A) and mountain flora (B) after filtering out the effect of altitude, climatic district and the interaction of the latter with January isotherm (with standard error bars). The residuals reflect the degree to which particular vegetation types differ in the presence of aliens after filtering out the effects given above. Horizontal lines show groups not significantly different by using least significant differences (LSD). Figures above/below columns are sample sizes.

mesophilous flora, the non-significant results in the case of the latter two vegetation types are obviously caused by a low number of samples (Fig. 4A). In other vegetation types, the proportion of aliens was significantly higher than in humid grasslands. In the mountain flora district (Fig. 4B), humid grasslands harboured the lowest proportion of aliens and this difference was significantly different from all other prevailing vegetation types where the number of samples (i.e. the number of reserves in the given category) allowed the test to be performed.

\subsection{Effect of position within the reserve network}

The reserves located outside protected landscape areas and national parks had on average $2.51 \%$ neophytes $($ S.E. $=2.35-2.68 \%$ ), while reserves located inside had $1.86 \% \quad($ S.E. $=1.67-2.10 \%)$, with the difference being highly significant $\left(\chi^{2}=8.42\right.$; d.f. $\left.=1 ; P=0.0037\right)$. This result was independent of all other explanatory variables considered.

\section{Discussion}

\subsection{Nature of the data and the effect of environmental factors}

Studies focusing on global patterns (Usher, 1988; Lonsdale, 1999) have yielded useful generalizations but are necessarily limited in (1) the level of detail desired, and (2) character of the data which must necessarily be taken from various sources that often differ in attitude, classification of plant immigration status, and taxonomical approach. This paper concentrates on a single temperate biome and, by using a large set of nature reserves that covers a wide range of habitat conditions and vegetation present in the area, it allows a detailed analysis of factors determining the extent of invasion on a regional scale. Working with species lists and using consistent classification ensures that the data obtained for particular reserves are directly comparable. In previously published analyses, the effects of explanatory variables were often hidden by their covariance structure. 
The statistical approach used in this paper allows us to evaluate the effects of particular factors, independent of other variables. The analysis thus gives a sound basis for unbiased discussion of regional patterns of plant invasions.

The set of reserves studied may be considered as a highly representative sample of natural vegetation of the study area. Hence the pattern found in the present study has general validity in terms of central European vegetation.

Studies on factors determining the extent of invasion at a landscape scale are rather rare, and various factors have been demonstrated to play a role. Timmins and Williams (1991) surveyed 234 New Zealand reserves and found the proximity of towns, distance from roads/railway lines, human use, reserve shape and habitat diversity to be the most important characteristics determining the degree of invasion. Positive effects of warmer climates on representation of alien species in the temperate zone has been repeatedly described (Kowarik, 1990; Dukes and Mooney, 1999) as well as the decrease of invasive plants with increasing altitude (Mihulka, 1998). The dominant effect of altitude found in our study is therefore not surprising, and reflects not only biological effects (many aliens coming from warmer regions are unable to complete their life cycle) but probably also a lower rate of diaspore release due to greater distance from concentrated seed sources. In temperate zones, the relationship between the extent of invasion and climate may become crucial in the future as a result of climate warming (Beerling, 1994; Dukes and Mooney, 1999) which will probably increase the invasibility of nature reserves located at higher altitudes.

The present study also seems to support the previously recognized relationship between the extent of invasion and number of human visitors (Macdonald et al., 1988; Usher, 1988; Lonsdale, 1999). Although data on the number of visitors are not available for the reserves studied, density of human population in a region taken as a measure of human impact had a significant effect on the invasion by neophytes, a group most closely related to recent human activities and potentially more dangerous to nature reserves than are archaeophytes.

\subsection{Extent of invasion in particular vegetation types}

Nature reserves studied in the present paper are invaded to various degrees, depending on the prevailing vegetation type. Humid, and dry grasslands to some extent also seem to be less invaded than other vegetation types, and this conclusion holds for districts of both mesophilous and mountain flora. If abiotic factors such as altitude and climate are removed, proportional representation of aliens results mainly from their interspecific interactions with native species. It can be theorised that such interactions are intensive in communities dominated by grasses (Pivello et al., 1999). Other studies have also documented low invasibility of grasslands (Hobbs and Atkins, 1988; Huenneke et al., 1990; Burke and Grime, 1996), including savanna (Lonsdale, 1999).

\subsection{Relationship between native and alien species: disturbance and competition}

As pointed out by Lonsdale (1999), native richness describes much of the variation in exotic richness because it reflects not only the area of the site but also its habitat diversity. Both negative relationships (Elton, 1958; Fox and Fox, 1986; Case and Bolger, 1991; Brown, 1995; Tilman, 1997, 1999; Knops et al., 1999) and positive relationships (Lonsdale 1999, see also May 1973; Case, 1996) between the richness of native flora and invasion have been reported. Lonsdale (1999) suggested that the positive relationship between alien and native species richness might simply be that richer plant communities are evidence of greater habitat diversity: both native and alien species respond to the greater habitat diversity in a similar positive way (see also Levine and D'Antonio, 1999) and there is no causal relationship between both groups measured at community scale. Exotic and native diversities are then supposed to be positively correlated without a casual link.

Nevertheless, our results here demonstrate a positive effect of the number of native species on the proportion of neophytes although the amount of variation explained is always small. The statistical procedure used ensures that this relationship cannot be considered as merely a side product of the relationship between reserve area and native species richness because it remained highly significant when the effect of area was removed. However, our results indicate that the relationship between native and alien richness is a more complex one (Levine and D'Antonio, 1999; Stohlgren et al., 1999).

To obtain closer insight into the complex nature of the relationship between native and alien species, we need to separate groups of aliens according to their immigration status. The negative, i.e. presumably competitive relationship to the native flora, was found for all aliens and obviously reflects the dominating influence of so-called archaeophytes (introduced as long ago as in the Neolithic period), while the opposite was true for socalled neophytes (newcomers to the flora introduced in the last 500 years). The positive relationship between the proportion of neophytes and native species richness can be explained by neophytes invading mostly in disturbed, heterogeneous environments where the role of direct competition with native flora can be lower and the presence of a disturbed site might be crucial for their establishment and naturalization. This conclusion is further supported by the positive effect of human pressure (expressed as human population density) on the 
representation of neophytes found in the present paper (Kowarik, 1990; Wittig, 1991; Pyšek, 1998).

These differences in the pattern of occurrence of groups with various immigration status indicate the importance of precise classification of species immigration status, whenever attempts at generalizations are to be made. Conclusions that Lonsdale (1999) made on the global scale are supported by our results for the neophytes, a group which better fits the definition of "an alien" in Anglo-Saxon and especially American literature, because there is often a tendency to consider only recent newcomers as aliens (Webb, 1985; Pyšek, 1995; Richardson et al., 2000b).

\subsection{Implication for nature conservation: SSISL instead of SLOSS?}

One of the most frequently debated theories in conservation biology has been whether several small reserves will contain more species than would a single reserve of equal total area (SLOSS). Arguments have been accumulated for support of both views. Large reserves are able to harbour larger populations and contain greater habitat diversity but well-designed and managed small scale reserves can effectively protect more populations of rare species than a single large area (Simberloff, 1986; Primack, 2000). However, the debate seems not to have universal solution because it is taxonomically biased: large reserves are more suitable for protection of large animals, while small areas seem to be more convenient in the case of invertebrates and plants (Schulz and Chang, 1998).

In nature conservation, the goal is usually to maximize species number per area. Rebelo and Siegfried (1992) point out that only when target species, i.e. those that should be protected, have been identified can the size of the constituent reserves be determined. However, in theoretical studies on design principles, total species number in a reserve is usually considered and it is rarely taken into account that alien species are an undesirable contribution to this figure. A large fraction of aliens are potentially invasive (Williamson, 1996) and successful invasion can have fatal consequences for diversity of invaded communities (Pyšek and Pyšek, 1995).

The question of whether or not small-scale nature reserves are more vulnerable to invasions than large ones has been repeatedly raised (Usher, 1988) but not rigorously answered. The results of our analysis do not support the hypothesis that small reserves are more invaded than large ones. A previous study (Pyšek et al., 2001) showed that the number of native species increased with reserve area and the relationship explained $18 \%$ of variation in the data. In the present study, there was a weak significant relationship between the occurrence of aliens and reserve area only when the effect of native species was removed. Moreover, remov- ing the effect of native richness is irrelevant from the pratical point of view of nature conservation because the decision about how large a reserve should be cannot disregard the native species it will harbour. It can therefore be concluded that from the viewpoint of reserve invasibility, the size of area does not play an important role in temperate nature reserves.

This paper demonstrates, in terms of the danger of invasion, an advantage to reserves surrounded by protected landscape over those not located inside national parks or protected landscape areas, because the former have significantly fewer neophytes. In central Europe, distinguishing the two groups of aliens according to immigration status is justified and has a long tradition (Holub and Jirásek, 1967; Pyšek, 1995; Richardson et al., 2000b). Of these two, only neophytes are dangerous as potential invaders to nature reserves. All major invasive species in the Czech flora are neophytes (Pyšek et al., 1995; Pyšek and Prach, 2001).

The results of the present study can therefore contribute to practical issues associated with reserve establishment and design. It can be concluded that while the 'natural' factors such as climate and composition of native flora are beyond control in the process of establishment of nature reserves, and reserve area is not important in terms of reserve invasibility, positioning the reserve within large protected sections of landscape significantly decreases probability of it being invaded by alien species. It appears that such landscapes, subjected to a special conservation regime, act as effective barriers to invasive species. For an alien species, it is easier to invade reserves located in a countryside with diverse land uses, which is more heavily affected by various human activities creating opportunities for their dispersal. We suggest a new model called Several Small Inside Single Large (SSISL) which seems to be an appropriate solution to maximize the species richness of nature reserves with regard to plant invasions.

\section{Acknowledgements}

We thank Dave Richardson and Marcel Rejmánek, Brian Davis, and two anonymous referees for helpful comments on the manuscript. Our thanks are due to Ludmila Kirschnerová for support, and to John Brock for improving our English. We thank Ivan Ostrý, Jan Wild and Danuše Vasilová for technical assistance. P.P. was supported by the grant No. 206/99/1239 from the Grant Agency of the Czech Republic and by grant no. AVOZ6005908 from Academy of Sciences of the Czech Republic, T.K. was supported by grant of the Grant Agency of the Czech Republic 206/99/P018. V.J. was supported by grant No. J13/98113100004 from the Ministry of Education of the Czech Republic (MS̆MT). The work was supported by the Agency for Nature 
Conservation and Landscape Protection of the Czech Republic, project No. M44 under the programme 610/2 "Environmental management" of the Ministry of Environment (MŽP).

\section{References}

Beerling, D., 1994. Predicting the response of the introduced species Fallopia japonica and Impatiens glandulifera to global climatic change. In: de Waal, L.C., Child, L.E., Wade, P.M., Brock, J.H. (Eds.), Ecology and Management of Invasive Riverside Plants. J. Wiley, pp. 135-139.

Berger, J.J., 1993. Ecological restoration and nonindigenous plant species: a review. Restoration Ecology 1, 74-82.

Brockie, R.E., Loope, L.L., Usher, M.B., Hamann, O., 1988. Biological invasions of island nature reserves. Biological Conservation 44, 9-36.

Brown, J.H., 1995. Macroecology. University of Chicago Press.

Burke, M.J.W., Grime, J.P., 1996. An experimental study of plant community invasibility. Ecology 77, 776-790.

Case, T.J., 1996. Global patterns in the establishment of exotic birds. Biological Conservation 78, 69-96.

Case, T.J., Bolger, D.T., 1991. The role of introduced species in shaping the abundance and distribution of island reptiles. Evolutionary Ecology 5, 272-290.

Cole, D.N., Landres, P.B., 1996. Threats to wilderness ecosystems: impacts and research needs. Ecological Applications 6, 168-184.

Collet, D., 1991. Modelling Binary Data. Chapman and Hall, London.

Cox, D.R., Snell, E.J., 1990. Analysis of Binary Data. Chapman and Hall, London.

Crawley, M.J., 1993. GLIM for Ecologists. Blackwell Sci. Publ, London.

Davis, M.A., Grime, P.J., Thompson, K., 2000. Fluctuating resources in plant communities: a general theory of invasibility. Journal of Ecology 88, 528-534.

Drake, J.A., Mooney, H.A., di Castri, F., Groves, R.H., Kruger, F.J., Rejmánek, M., Williamson, M. (Eds.), 1989. Biological Invasions: a Global Perspective. John Wiley, Chichester.

Duffey, E., Usher, M.B., 1988. Biological invasions of nature reserves. Biological Conservation 44, 1-135.

Dukes, J.S., Mooney, H.A., 1999. Does global change increase the success of biological invaders? Trends in Ecology and Evolution 14, $135-139$.

Elton, C.S., 1958. The Ecology of Invasions by Animals and Plants. Methuen, London.

Fox, M.D., Fox, B.J., 1986. The susceptibility of natural communities to invasion. In: Groves, R.H., Burdon, J.J. (Eds.), Ecology of Biological Invasions. Cambridge University Press, Cambridge, pp. 57-66.

Francis, B., Green, M., Payne, C., 1994. The GLIM System. Release 4 manual. Clarendon Press, Oxford.

Gordon, D.R., 1998. Effects of invasive, non-indigenous plant species on ecosystem processes: lessons from Florida. Ecological Applications 8, 975-989.

Groves, R.H., Burdon, J.J., 1986. Ecology of Biological Invasions: An Australian Perspective. Australian Academy of Sciences, Canberra.

Hejný, S., Slavík, B. (Eds.), 1988. Flora of the Czech Republic, Vol. 1. Academia, Praha. (In Czech).

Hobbs, R.J., Atkins, L., 1988. Effect of disturbance and nutrient addition on native and introduced annuals in plant communities in the Western Australia wheatbelt. Australian Journal of Ecology 13, 171-179.

Holdgate, M.W., 1986. Summary and conclusions: characteristics and consequences of biological invasions. Philosophical Transactions of the Royal Society of London B314, 733-742.

Holt, R.A., 1992. Control of alien plants on nature conservancy preserves. In: Stone, C.P., Smith, C.W., Tunison, J.T. (Eds.), Alien
Plants Invasions in Native Ecosystems of Hawaii: Management and Research. University Hawaii Press, Honolulu, pp. 525-535.

Holub, J., Jirásek, V., 1967. Zur Vereinheitlichung der Terminologie in der Phytogeographie. Folia Geobotanica \& Phytotaxonomica 2, 69 113.

Holub, J., Procházka, F., 2000. Red List of vascular plants of the Czech Republic-2000. Preslia 72, 187-230.

Huenneke, L.F., Hamburg, S.P., Koide, R., Mooney, H.A., Vitousek, P.M., 1990. Effects of soil resources on plant invasion and community structure in Californian serpentine grassland. Ecology 71, 478-491.

Knops, J.M.H., Tilman, D., Haddad, N.M., Naeem, S., Mitchell, C.E., Haarstad, J., Ritchie, M.E., Howe, K.M., Reich, P.B., Siemann, E., Groth, J., 1999. Effects of plant species richness on invasion dynamics, disease outbreaks, insect abundances and diversity. Ecology Letters 2, 286-293.

Kornberg, H., Williamson, M.H., 1987. Quantitative aspects of the ecology of biological invasions. Philosophical Transactions of the Royal Society of London B314.

Kos, J., Maršálková, M., 1997. Protected Areas of the Czech Republic. Agency for Nature Conservation and Landscape Protection of the Czech Republic, Prague. (In Czech).

Kowarik, I., 1990. Some responses of flora and vegetation to urbanization in Central Europe. In: Sukopp, H., Hejný, S., Kowarik, I. (Eds.), Urban Ecology. SPB, The Hague, pp. 45-74.

Kowarik, I., 1995. On the role of alien species in urban flora and vegetation. In: Pyšek, P., Prach, K., Rejmánek, M., Wade, M. (Eds.), Plant Invasions: General Aspects and Special Problems. SPB, Amsterdam, pp. 85-103.

Levine, J.M., D'Antonio, C.M., 1999. Elton revisited: a review of evidence linking diversity and invasibility. Oikos 87, 15-26.

Lonsdale, W.M., 1999. Global patterns of plant invasions and the concept of invasibility. Ecology 80, 1522-1536.

Loope, L.L., 1992. An overview of problems with introduced plant species in national parks and biospherical reserves. In: Stone, C.P., Smith, C.W., Tunison, J.T. (Eds.), Alien Plants Invasions in Native Ecosystems of Hawaii: Management and Research. University Hawaii Press, Honolulu, pp. 3-28.

Macdonald, I.A.W., Kruger, F.J., Ferrar, A.A., 1986. The Ecology and Management of Biological Invasions in Southern Africa. Oxford University Press, Cape Town.

Macdonald, I.A.W., Graber, D.M., DeBenedetti, S., Groves, R.H., Fuentes, E.R., 1988. Introduced species in nature reserves in Mediterranean type climatic regions of the World. Biological Conservation 44, 37-66.

Macdonald, I.A.W., Loope, L.L., Usher, M.B., Hamann, O., 1989. Wildlife conservation and the invasion of nature reserves by introduced species: a global perspective. In: Drake, J.A.et al. (Ed.), Biological Invasions: A Global Perspective. John Wiley, Chichester, UK, pp. 215-255.

Maršálková-Němejcová, M., Mihálik, S̆. (Eds.), 1977. National Parks, Nature Reserves and Other Nature Protected Areas in Czechoslovakia. Academia, Praha. (In Czech).

May, R.M., 1973. Stability and Complexity in Model Ecosystems. Princeton University Press, Princeton.

McCullagh, P., Nelder, J.A., 1989. Generalized Linear Models. Chapman and Hall, London.

Mihulka, S., 1998. The effect of altitude on the pattern of plant invasions: a field test. In: Starfinger, U., Edwards, K., Kowarik, I., Williamson, M. (Eds.), Plant Invasions: Ecological Mechanisms and Human Responses. Backhuys, Leiden, pp. 313-320.

Mooney, H.A., Drake, J.A. (Eds.), 1986. Ecology of Biological Invasions of North America and Hawaii. Springer Verlag, New York.

Opravil, E. 1980. The history of synanthropic vegetation, 1-6. Zira, Praha, 28:4-5, 53-55, 88-90, 130-131, 167-168, 206-207 (in Czech).

Pivello, V.R., Shida, C.N., Meirelles, S.T., 1999. Alien grasses in Brazilian savannas: a threat to the biodiversity. Biodiversity and Conservation 8, 1281-1294. 
Primack, R.B., 2000. A Primer of Conservation Biology. Sinauer Publ, Sunderland.

Pyšek, P., 1995. On the terminology used in plant invasion studies. In: Pyšek, P., Prach, K., Rejmánek, M., Wade, M. (Eds.), Plant Invasions: General Aspects and Special Problems. SPB, Amsterdam, pp. 71-81.

Pyšek, P., 1998. Alien and native species in Central European urban floras: a quantitative comparison. Journal of Biogeography 25, 155163.

Pyšek, P., Pyšek, A., 1995. Invasion by Heracleum mantegazzianum in different habitats in the Czech Republic. Journal of Vegetation Science 6, 711-718.

Pyšek, P., Prach, K., 2001. Research in plant invasions in the Czech Republic: history and focus. Biological Invasions. in press..

Pyšek, P., Prach, K., Rejmánek, M., Wade, M. (Eds.), 1995. Plant Invasions: General Aspects and Special Problems. SPB, Amsterdam.

Pyšek, P., Kučera, T., Jarošík, V., 2001. Factors determining plant species richness of nature reserves: the interplay of area, climate and habitat in central European landscape. Global Ecology and Biogeography Letters.

Quitt, E., 1975. Climatic Regions of the Czech Socialist Republic. Institute of Geography, Czech Academy of Sciences, Brno. (In Czech).

Rebelo, A.G., Siegfried, W.R., 1992. Where should nature-reserves be located in the cape floristic region, South-Africa-models for the spatial configuration of a reserve network aimed at maximizing the protection of floral diversity. Conservation Biology 6, 243-252.

Rejmánek, M., 1996. A theory of seed plant invasiveness: the first sketch. Biological Conservation 78, 171-181.

Rejmánek, M., 1999. Invasive plant species and invasible ecosystems. In: Sandlund, O.T., Schei, P.J., Viken, A. (Eds.), Invasive Species and Biodiversity Management. Kluwer, Dordrecht, pp. 79-102.

Richardson, D.M., Allsopp, N., D’Antonio, C., Milton, S.J., Rejmánek, M., 2000a. Plant invasions - the role of mutualisms. Biological Review 75, 65-93.

Richardson, D.M., Pyšek, P., Rejmánek, M., Barbour, M.G., Panetta, F.D., West, C.J., 2000b. Naturalization and invasion of alien plantsconcepts and definitions. Diversity and Distributions 6, 93-107.
Schroeder, F.G., 1969. Zur Klassifizierung der Anthropochoren. Vegetatio 16, 225-238.

Schulz, C.B., Chang, G.C., 1998. Challenges in insect conservation: managing fluctuating populations in disturbed habitats. In: Fiedler, P.L., Kareiva, P.M. (Eds.), Conservation Biology for the Coming Decade. Chapman and Hall, New York, pp. 228-254.

Simberloff, D., 1986. Design of nature reserves. In: Usher, M.B. (Ed.), Wildlife Conservation Evaluation. Chapman and Hall, London, pp. 316-337.

Sokal, R., Rohlf, F.J., 1981. Biometry. Freeman, San Francisco,

Stohlgren, T.J., Binkley, D., Chong, G.W., Kalkhan, M.A., Schell, L.D., Bull, K.A., Otsuki, Y., Newman, G., Bashkin, M., Son, Y., 1999. Exotic plant species invade hot spots of native plant diversity. Ecological Monographs 69, 25-46.

Tilman, D., 1997. Community invasibility, recruitment limitation and grassland biodiversity. Ecology 78, 81-92.

Tilman, D., 1999. The ecological consequences of changes in biodiversity: a search for general principles. Ecology 80, 1455-1474.

Timmins, S.M., Williams, P.A., 1991. Weed numbers in New Zealand's forest and scrub reserves. New Zealand Journal of Ecology 15, $153-162$.

Usher, M.B., 1988. Biological invasions of nature reserves: a search for generalisation. Biological Conservation 44, 119-135.

Usher, M.B., 1991. Biological invasions into tropical nature reserves. In: Ramakrishnan, P.S. (Ed.), Ecology of Biological Invasions in the Tropics. International Scientific Publishers, New Delhi, pp. 21-34.

Usher, M.B., Kruger, F.J., Macdonald, I.A.W., Loope, L.L., Brockie, R.E., 1988. The ecology of biological invasions into nature reserves: an introduction. Biological Conservation 44, 1-9.

Vesecký, A., Petrovič, Š., Briedoň, V., Karský, V., 1958. Climatic Atlas of Czechoslovakia. Praha (in Czech).

Vitousek, P.M., 1990. Biological invasions and ecosystem processes: towards an integration of population biology and ecosystem studies. Oikos 57, 7-13.

Webb, D.A., 1985. What are the criteria for presuming native status? Watsonia 15, 231-236.

Williamson, M., 1996. Biological Invasions. Chapman and Hall, London. Wittig, R., 1991. Ökologie der Grossstadtflora. G. Fischer, Stuttgart. 